\title{
Zatorowość paradoksalna ośrodkowego układu nerwowego u pacjenta z ostrą zatorowością płucną wysokiego ryzyka
}

\author{
Paradoxical embolism of the central nervous system \\ in a patient with high risk acute pulmonary embolism
}

\author{
Sylwia Goliszek ${ }^{1}$, Katarzyna Kurnicka ${ }^{1}$, Barbara Lichodziejewska ${ }^{1}$, Marek Roik ${ }^{1}$, \\ Michał Ciurzyński ${ }^{1}$, Małgorzata Wiśniewska ${ }^{2}$, Marek Babiuch ${ }^{3}$, Piotr Pruszczyk ${ }^{1}$ \\ ${ }^{1}$ Klinika Chorób Wewnętrznych i Kardiologii z Centrum Diagnostyki i Leczenia ŻyInej Choroby Zakrzepowo-Zatorowej, \\ Warszawski Uniwersytet Medyczny \\ ${ }^{2}$ I Zakład Radiologii Klinicznej, Warszawski Uniwersytet Medyczny \\ ${ }^{3}$ Szpital Kliniczny Dzieciątka Jezus w Warszawie
}

\section{Streszczenie}

Zatorowość paradoksalna ośrodkowego układu nerwowego u pacjentów z ostrą zatorowością płucną zdarza się stosunkowo często, jednak w większości przypadków udar niedokrwienny jest bezobjawowy, wykrywany jedynie na podstawie badań obrazowych. Objawy neurologicznie występują tylko u około 1/4 pacjentów, ale mogą być przyczyną trwałego inwalidztwa. W pracy opisano przypadek pacjenta z ostrą zatorowością płucną, który przebył jednocześnie rozległy udar niedokrwienny mózgu.

Słowa kluczowe: zatorowość paradoksalna, udar niedokrwienny, ostra zatorowość płucna

(Folia Cardiologica 2015; 10, 4: 302-305)

\section{Wstęp}

Ostra zatorowość płucna w 6-17\% przypadków może być powikłana zatorowością paradoksalną ośrodkowego układu nerwowego (OUN). Nie ma odrębnych wytycznych dotyczących profilaktyki wtórnej udaru niedokrwiennego w tej grupie pacjentów. Poniżej przedstawiono przypadek pacjenta i zaproponowany sposób postępowania w tej szczególnej sytuacji klinicznej.

\section{Opis przypadku}

Mężczyzna 65-letni z cukrzycą typu 2 i nadciśnieniem tętniczym został przyjęty na szpitalny oddział ratunkowy szpitala miejskiego po zasłabnięciu poprzedzonym nagłą dusznością spoczynkową. Przy przyjęciu stwierdzono hipoksemię z saturacją 85\%, tachykardię około 125/min i symetryczne obrzęki kończyn dolnych. Ciśnienie tętnicze było prawidłowe. W echokardiografii przezklatkowej (TTE, transthoracic echocardiography) uwidoczniono cechy przeciążenia prawej komory. Na podstawie obrazu klinicznego i echokardiograficznego wysunięto podejrzenie ostrej zatorowości płucnej. Ze względu na brak możliwości natychmiastowego wykonania angiografii metodą tomografii komputerowej (angio-CT, computed tomography) klatki piersiowej pacjent otrzymał dożylnie heparynę niefrakcjonowaną. Po kilku godzinach hospitalizacji wystąpiły objawy wstrząsu. Pacjentowi podano dożylnie streptokinazę w dawce 1,5 mln jm., dopaminę i dobutaminę, a następnie kontynuowano leczenie heparyną niefrakcjonowaną. Po kilkunastu godzinach od trombolizy wystąpiły zaburzenia widzenia, niedowład połowiczy prawostronny i afazja. Pacjenta przekazano na oddział

Adres do korespondencji: lek. Sylwia Goliszek, Klinika Chorób Wewnętrznych i Kardiologii z Centrum Diagnostyki i Leczenia Żylnej Choroby Zakrzepowo-Zatorowej, Warszawski Uniwersytet Medyczny, ul. Lindleya 4, 02-005 Warszawa, e-mail: s.goliszek@poczta.onet.pl 


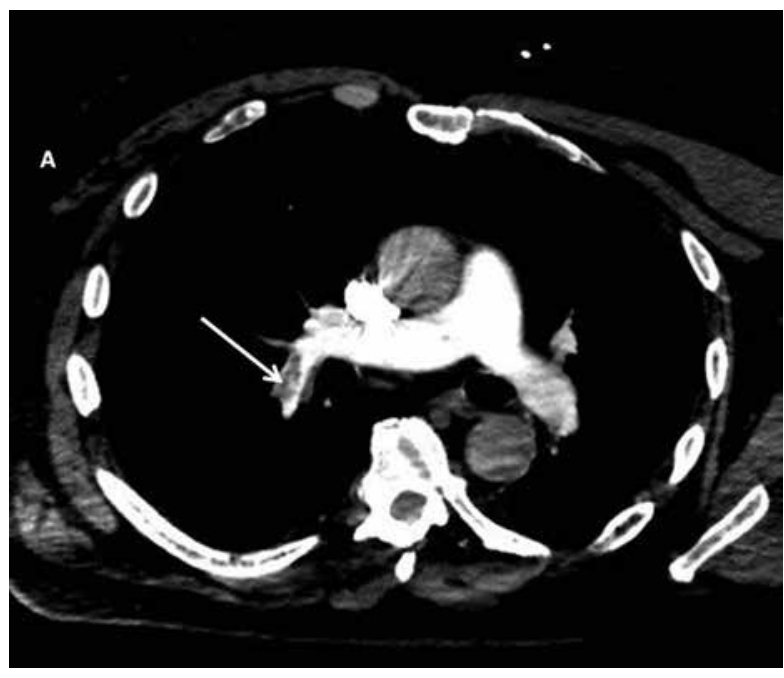

Rycina 1. Angiografia klatki piersiowej metodą tomografii komputerowej uwidaczniająca skrzeplinę $w$ tętnicy do płata dolnego prawego płuca (strzałka)

intensywnej opieki kardiologicznej (OIOK) Kliniki Chorób Wewnętrznych i Kardiologii z Centrum Diagnostyki i Leczenia Żylnej Choroby Zakrzepowo-Zatorowej Warszawskiego Uniwersytetu Medycznego. W pilnie wykonanej angio-CT klatki piersiowej potwierdzono ostrą zatorowość płucną, uwidoczniając liczne skrzepliny w tętnicach płucnych (ryc. 1). W jednoczasowo wykonanej CT głowy bez podania kontrastu uwidoczniono ognisko rozległego ostrego udaru niedokrwiennego z dorzecza lewej tętnicy środkowej mózgu z cechami obrzęku (ryc. 2). Co istotne, nie uwidoczniono cech krwawienia do OUN. Przy przyjęciu do Kliniki pacjent był w średnio ciężkim stanie ogólnym, przytomny, z afazją mieszaną, niedowładem połowiczym prawostronnym i objawami centralnego porażenia nerwu twarzowego po prawej stronie. W 1. dobie hospitalizacji stan hemodynamiczny chorego uległ znacznej poprawie; odstawiono katecholaminy. W ramach diagnostyki przyczyny udaru niedokrwiennego wykonano TTE z kontrastem w celu oceny drożności otworu owalnego (PFO, patent foramen ovale). Uwidoczniono liczne pęcherzyki kontrastu w jamach lewego serca we wczesnej fazie od ich podania. Obecność PFO ostatecznie potwierdzono w echokardiografii przezprzełykowej (ryc. 3). U pacjenta nie stwierdzono innych potencjalnych przyczyn wystąpienia udaru mózgu - nie zarejestrowano migotania przedsionków podczas monitorowania na OIOK i w późniejszym zapisie elektrokardiograficznym (EKG) metodą Holtera oraz nie stwierdzono zaburzeń przepływu w tętnicach szyjnych w ultrasonografii doplerowskiej. Ostatecznie rozpoznano idiopatyczną zatorowość płucną wysokiego ryzyka powikłaną udarem niedokrwiennym z dorzecza lewej tętnicy środkowej mózgu w mechanizmie zatorowości paradoksalnej przez PFO. Wspólnie z neurologiem podję-

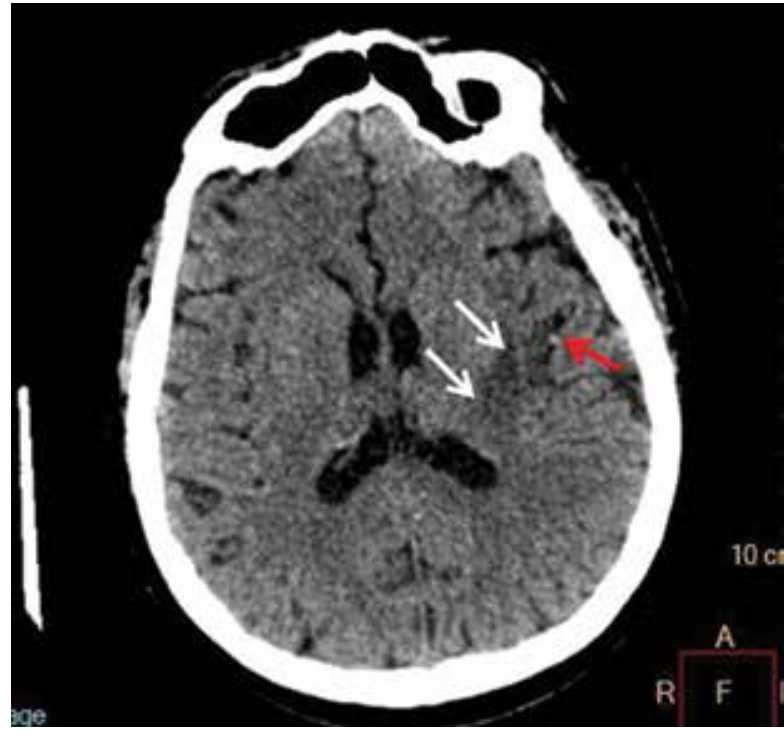

Rycina 2. Tomografia komputerowa głowy bez podania środka cieniującego uwidaczniająca obszary obniżonej densyjności w lewym płacie skroniowym - udar niedokrwienny z dorzecza tętnicy mózgu środkowej lewej (białe strzałki); hiperdensyjny wykrzepiony odcinek M3 tętnicy środkowej mózgu lewej (czerwona strzałka)

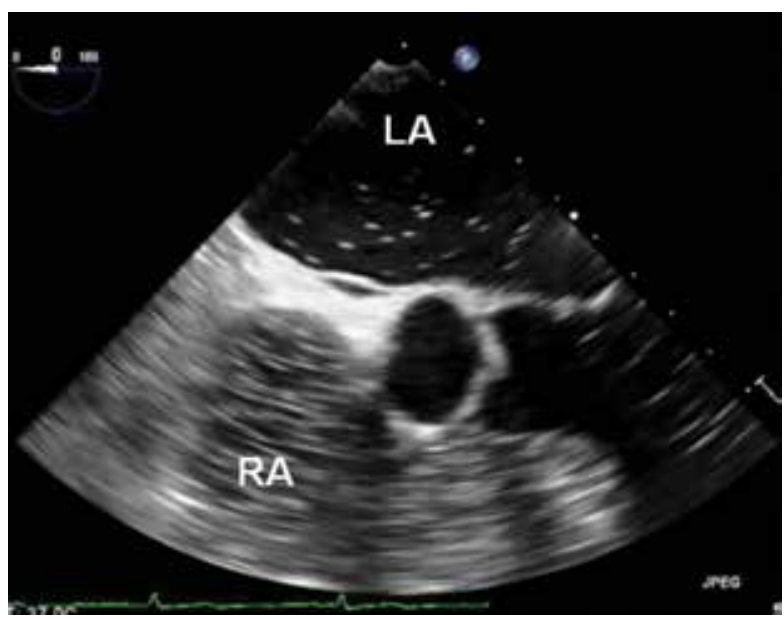

Rycina 3. Echokardiografia przezprzełykowa z kontrastem. Pęcherzyki kontrastu widoczne w prawym przedsionku (RA, right atrium) i lewym przedsionku (LA, left atrium)

to decyzję o zamknięciu PFO. Po 6 miesiącach pełnego leczenia przeciwkrzepliwego i rehabilitacji neurologicznej u pacjenta przeprowadzono w tej samej Klinice niepowikłany przezskórny zabieg zamknięcia PFO okluderem Figulla Flex II (ryc. 4, 5). Po zabiegu pacjentowi zalecono przyjmowanie kwasu acetylosalicylowego w dawce $100 \mathrm{mg} /$ dobe bezterminowo oraz klopidogrel w dawce $75 \mathrm{mg} /$ dobę przez miesiąc. Przy wypisywaniu ze szpitala pacjent był w dobrym 
stanie, z jedynie dyskretnym ośrodkowym prawostronnym niedowładem nerwu VII oraz parestezjami w obrębie prawej kończyny górnej.

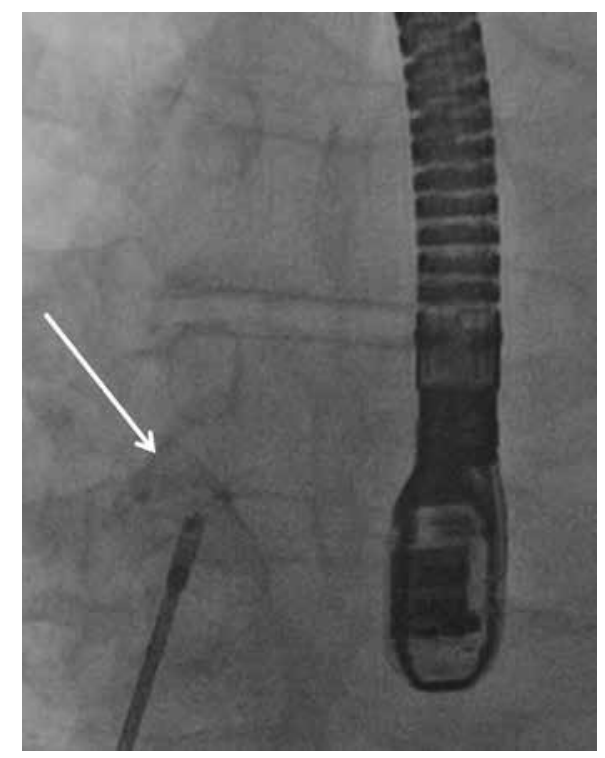

Rycina 4. Obraz skopii okołozabiegowej. Widać wszczepiony okluder Figulla Flex II (strzałka)

\section{Omówienie}

W każdym przypadku udaru paradoksalnego mózgu należy rozważyć jednoczasowe wystąpienie udaru z innej przyczyny, na przykład w przebiegu migotania lub trzepotania przedsionków czy istotnego hemodynamicznie zwężenia tętnicy szyjnej. U opisanego pacjenta z ostrą zatorowością płucną i dużym przeciążeniem prawej komory było wysoce prawdopodobne, że udar niedokrwienny powstał w mechanizmie zatoru paradoksalnego. Potencjalnie duże ryzyko nawrotu zatorowości płucnej oraz rozległy obszar niedokrwienia mózgu były podstawami do kwalifikacji pacjenta do przezskórnego zamknięcia PFO.

\section{Podsumowanie}

Profilaktykę wtórną zatorowości paradoksalnej mózgu należy rozpatrywać indywidualnie u każdego pacjenta, biorąc pod uwage mechanizm udaru, jego rozległość oraz ryzyko nawrotu ostrej zatorowości płucnej.

\section{Konflikt interesów}

Autorzy nie zgłaszają konfliktu interesów.
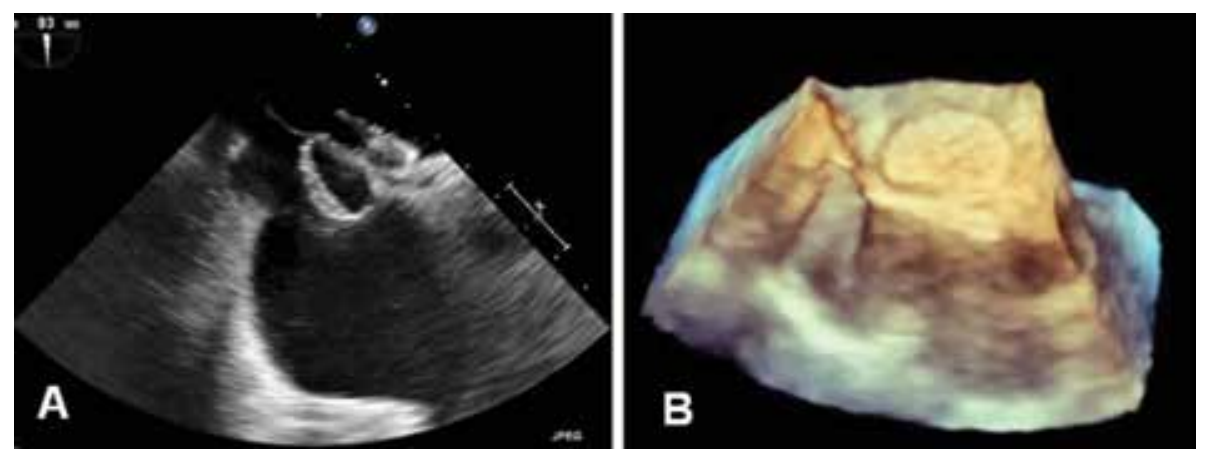

Rycina 5. Echokardiografia przezprzełykowa z uwidocznionym wszczepionym okluderem Figulla Flex II: A. Obraz 2D; B. Obraz 3D

\section{Abstract}

Paradoxical embolism of the central nervous system in patients with acute pulmonary embolism occurs relatively frequently. Ischaemic stroke is often asymptomatic, detected only thanks to imaging. Neurological symptoms occur only in approximately $1 / 4$ of patients, but can cause permanent disability. In this case, we present a case of a patient with acute pulmonary embolism, who, at the same time, had a large ischaemic stroke.

Key words: paradoxical embolism, ischaemic stroke, acute pulmonary embolism

(Folia Cardiologica 2015; 10, 4: 302-305) 


\section{Piśmiennictwo}

1. Kasper W., Geibel A., Tiede N., Just H. Patent foramen ovale in patients with haemodynamically significant pulmonary embolism. The Lancet 1992; 340: 561-564.

2. Konstantinides S., Geibel A., Kasper W. i wsp. Patent foramen ovale is an important predictor of adverse outcome in patients with major pulmonary embolism. Circulation 1998; 97: 1946-1951.

3. Clergeau M.R., Hamon M., Morello R. i wsp. Silent cerebral infarcts in patients with pulmonary embolism and a patent foramen ovale: a prospective diffusion-weighted MRI study. Stroke 2009; 40: 3758-3762.
4. Doyen D., Castellani M., Moceri P. i wsp. Patent foramen ovale and stroke in intermediate-risk pulmonary embolism. Chest 2014; 146 : 967-973.

5. Goliszek S., Wiśniewska M., Kurnicka K. i wsp. Patent foramen ovale increases the risk of acute ischemic stroke in patients with acute pulmonary embolism leading to right ventricular dysfunction. Thromb. Res. 2014; 134: 1052-1056.

6. Demkov M., Rużyłło W., Kępka C. i wsp. Przezskórne zamykanie drożnego otworu owalnego u chorych z kryptogennym udarem mózgu. Kardiol Pol. 2004; 61: 101-109.

\section{Komentarz}

\section{Zatorowość płucna i drożny otwór owalny - jak bardzo niebezpieczna kombinacja?}

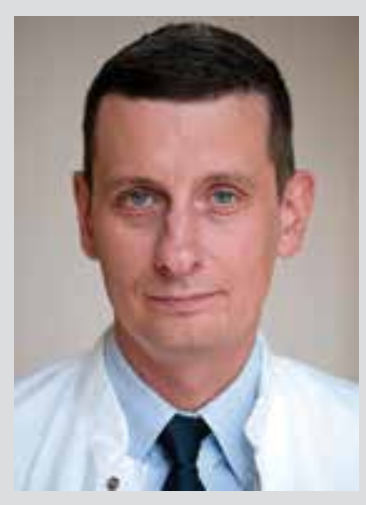

\section{dr hab. med. Marcin Kurzyna, prof. CMKP}

Klinika Krążenia Płucnego i Chorób Zakrzepowo-Zatorowych Centrum Medycznego Kształcenia Podyplomowego, Europejskie Centrum Zdrowia Otwock

0 istniejącym drożnym otworze owalnym (PFO, patent foramen ovale) u pacjentów z zatorowością płucną (PE, pulmonary embolism) najczęściej dowiadujemy się, oglądając mrożące krew w żyłach obrazy skrzeplin „w podróży”, które zatrzymywały się w jamach prawego serca. Skrzepliny takie często wklinowują się w PFO, przechodzą do lewego przedsionka i powodują objawy zatorowości systemowej [1, 2]. Mimo braku dowodów z badań klinicznych, większość ekspertów zaleca w takiej sytuacji leczenie kardiochirurgiczne, obawiając się fragmentacji skrzeplin w lewym sercu po zastosowaniu trombolizy [3].

W przypadku opisywanym przez dr Goliszek i wsp. nie uwidoczniono „skrzepliny w podróży”, ale raczej nie ma wątpliwości, że to właśnie zatorowość skrzyżowana była źródłem udaru niedokrwiennego. Chociaż, jak słusznie zauważają Autorzy, zawsze należy wykluczyć krwawienie do ośrodkowego układu nerwowego (OUN) (streptokinaza!) oraz inne przyczyny udaru niedokrwiennego. To ostatnie może być jednak trudne u 65-letniego pacjenta z nadciśnieniem tętniczym i cukrzycą. Opisywana sytuacja pokazuje, że w grupie pacjentów, u których występuje PE, PFO może mieć negatywne skutki dla przebiegu PE o wiele częściej, niż wynikałoby to z częstości wykrywanych „skrzeplin w podróży”. We wcześniejszej pracy Autorzy przedstawianego przypadku opisywali PFO u 19 spośród 55 (34\%) pacjentów z PE [4]. W 4 przypadkach stwierdzono epizod niedokrwienia OUN w badaniu rezonansu magnetycznego, w tym tylko u 1 pacjenta był on związany z występowaniem objawów klinicznych. Wszystkie epizody niedokrwienia OUN wystąpiły u pacjentów z PFO i przeciążeniem ciśnieniowym prawej komory, co wiąże się ze wzrostem ciśnienia w prawym przedsionku i stwarza warunki hemodynamiczne do stałego przecieku prawo-lewego. Doyen i wsp. [5] w grupie 41 pacjentów z PE umiarkowanego ryzyka ocenili częstość PFO na 56,1\%, jeśli diagnozę stawiano za pomocą echokardiografii przezprzełykowej i na 19,5\%, jeśli wykorzystywano standardowe badanie przez ścianę klatki piersiowej. Udar niedokrwienny wystąpił w 17,1\% przypadków i zawsze wiązał się z istotnym przeciekiem przez PFO.

Bezobjawowe udary niedokrwienne związane z zatorowością skrzyżowaną mogą ulec wtórnemu ukrwotocznieniu po zastosowaniu leczenia trombolitycznego. Można tylko spekulować, na ile wysoka liczba udarów krwotocznych w grupie objętej leczeniem trombolitycznym w badania PEITHO mogła mieć związek z bezobjawową zatorowością skrzyżowaną [6].

Kolejną nierozstrzygniętą kwestią jest celowość przezskórnego zamykania PFO w profilaktyce wtórnej udaru mózgu. Intuicyjnie czujemy, że ten dość prosty zabieg interwencyjny może uchronić pacjenta przed kolejnymi epizodami niedokrwiennymi skuteczniej niż farmakoterapia. W randomizowanych badaniach klinicznych [7] i metaanalizach [8, 9] nie potwierdzono jednoznacznie wyższości leczenia zabiegowego nad leczeniem przeciwpłytkowym lub przeciwkrzepliwym. Dodatkowo u pacjentów wymagających przewlekłej antykoagulacji z powodu PE nawet czasowe dołączenie jednego lub dwóch leków przeciwpłytkowych może zwiększać ryzyko powikłań krwotocznych. Z drugiej strony zamknięcie PFO może być celowe u chorych, u których planuje się zaprzestanie leczenia przeciwkrzepliwego po kilkumiesięcznym okresie 
leczenia PE - tak jak w opisywanym przypadku. Z kolei w sytuacji rozwoju zakrzepowo-zatorowego nadciśnienia płucnego i rozwoju niewydolności prawej komory pozostawienie PFO może być korzystne. Przeciek prawo-lewy przez PFO może działać jak septostomia przedsionkowa w idiopatycznym nadciśnieniu płucnym [10].

Opisany przypadek i dane z piśmiennictwa jasno wskazują, że należy się liczyć z większym odsetkiem powikłań wtedy, gdy PE wspótistnieje z PFO. Nadal jednak nie wiadomo, czy powinniśmy rutynowo rozszerzać badanie echokardiograficzne wykonywane u pacjenta z PE o podanie kontrastu i aktywnie poszukiwać PFO. Należy mieć nadzieję, że kolejne lata dadzą odpowiedź na pytanie, czy obecność PFO powinna modyfikować nasze postępowanie terapeutyczne w ostrej (tromboliza) i przewlekłej (zabiegowe zamknięcie) fazie leczenia PE.

\section{Piśmiennictwo}

1. Grzelakowski P., Lugowski T., Kurzyna M. i wsp. [Acute intermediate-risk pulmonary embolism with right-sided free-floating intracardiac thrombus, systemic inflammatory reaction syndrome, multiple organ dysfunction syndrome, disseminated intravascular coagulation and acute ischaemia of a limb]. Kardiol. Pol. 2010; 68: 1140-1144.

2. Smith J.G., Koul S., Roijer A. i wsp. Acute right ventricular failure caused by concomitant coronary and pulmonary embolism: successful treatment with endovascular coronary and pulmonary thrombectomy. Eur. Heart J. Acute Cardiovasc. Care 2013; 2: 131-136.

3. Torbicki A., Galie N., Covezzoli A. i wsp. Right heart thrombi in pulmonary embolism: results from the International Cooperative Pulmonary Embolism Registry. J. Am. Coll. Cardiol. 2003; 41: 2245-2251.

4. Goliszek S., Wisniewska M., Kurnicka K. i wsp. Patent foramen ovale increases the risk of acute ischemic stroke in patients with acute pulmonary embolism leading to right ventricular dysfunction. Thromb. Res. 2014; 134: 1052-1056.
5. Doyen D., Castellani M., Moceri P. i wsp. Patent foramen ovale and stroke in intermediate-risk pulmonary embolism. Chest 2014; 146: 967-973.

6. Meyer G., Vicaut E., Danays T. i wsp. Fibrinolysis for patients with intermediate-risk pulmonary embolism. N. Engl. J. Med. 2014; 370: 1402-1411.

7. Carroll J.D., Saver J.L., Thaler D.E. i wsp. Closure of patent foramen ovale versus medical therapy after cryptogenic stroke. N. Engl. J. Med. 2013; 368: 1092-1100.

8. Rengifo-Moreno P., Palacios I.F., Junpaparp P. i wsp. Patent foramen ovale transcatheter closure vs. medical therapy on recurrent vascular events: a systematic review and meta-analysis of randomized controlled trials. Eur. Heart J. 2013; 34: 3342-3352.

9. Pickett C.A., Villines T.C., Ferguson M.A., Hulten E.A. Percutaneous closure versus medical therapy alone for cryptogenic stroke patients with a patent foramen ovale: meta-analysis of randomized controlled trials. Tex. Heart Inst. J. 2014; 41: 357-367.

10. Glanville A.R., Burke C.M., Theodore J., Robin E.D. Primary pulmonary hypertension. Length of survival in patients referred for heart-lung transplantation. Chest 1987; 91: 675-681. 